\title{
REPRESENTACIONES DE GÉNERO EN LA PUBLICIDAD DE ALIMENTOS: \\ UN ANÁLISIS DE CONTENIDO
}

\author{
Eva Espinar Ruiz \\ eva.espinar@ua.es \\ Universidad de Alicante \\ Cristina González Díaz \\ cristina.gdiaz@ua.es \\ Universidad de Alicante
}

Recibido: 01-02-2012

Aceptado: 15-03-2012

\section{Resumen}

El análisis de contenido del mensaje mediático desde una perspectiva de género cuenta ya con una abundante bibliografía. En el caso de la publicidad, gran parte de los estudios realizados se han centrado en muestras genéricas de contenidos publicitarios o en aquella publicidad tradicionalmente asociada a uno u otro género. Sin embargo, pocos autores han analizado los contenidos de género de la publicidad relativa a productos de alimentación, a pesar de la estrecha relación entre estructuras de género y los procesos sociales de compra y preparación de alimentos. En este ámbito se sitúa, precisamente, nuestra investigación. Los principales resultados obtenidos muestran claras diferencias de género en las piezas publicitarias: tanto en términos de presencia cuantitativa como en la asignación de determinadas características.

Palabras clave: Género, publicidad, alimentación, televisión, análisis de contenido.

\begin{abstract}
Content analysis of mass media messages from a gender perspective has a long tradition. With regard to advertising, much of the studies have focused on generic samples of advertising contents or on sectors traditionally associated with one or another gender. However, few authors have analyzed gender representations in food advertising, despite the close relationship between gender relations and social processes of buying and preparing food. This is, precisely, the field of our research. Some of the main results show clear gender differences in the advertisements: both in terms of quantitative presence and in the allocation of certain characteristics.
\end{abstract}

Keywords: Gender, advertising, food, television, content analysis. 


\section{Introducción}

Los medios de comunicación se han convertido en una de las principales fuentes de información para los seres humanos. Intervienen en la socialización de las personas mostrando una determinada representación "del entorno (material, social, ideal) y de lo que en él acontece" (Martín Serrano, 2004: 40). Dicho de otra forma, los medios de comunicación configuran "una representación de [la] realidad con consecuencias enculturizadoras, afectando al sistema de normas culturales, los valores, las creencias y las actitudes de las personas" (Younis, 2008: 303-304).

Desde la teoría social cognitiva (Bandura, 1994:85) se destaca que los medios de comunicación tienen la capacidad de influir en las creencias, actitudes y comportamientos de la población en la medida en que muestran modelos que pueden ser observados por la audiencia. En concreto, es así como se han convertido en mediadores fundamentales (Martín Serrano, 2004:56) a la hora de conformar las percepciones que tenemos de hombres y mujeres, así como "actitudes e, incluso, identidades de género" (Stern y Mastro, 2004: 216).

Por su parte, la publicidad, independientemente de la intención principal de los emisores, "transmite - lo quiera o no- estilos de vida, propuestas sobre cómo se debe ser, actuar, consumir, para tener éxito en la escala social" (Díaz Soloaga, 2007: 28). Es decir, la publicidad no ofrece únicamente productos, "sino también modelos de actitudes, formas de vida e imágenes paradigmáticas que orientan y, en muchos casos, definen las necesidades y los deseos de las personas" (Peña y Frabetti, 1990: 5). De esta forma, "advertising is an effective and pervasive medium of influence and persuasion, and its influence is cumulative, often subtle, and primarily unconscious" (Kilbourne, 1999: 67). De acuerdo con Erving Goffman (1979), la publicidad nos transmite, implícitamente, quiénes deberíamos ser. En materia de género, tanto los estudios del propio Goffman como las investigaciones más recientes (Ganahl, Prinsen y Netzley, 2003; Royo, Aldas, Küster y Vila, 2008; Gentry y Harrison, 2010), suelen coincidir en afirmar que, en líneas generales, la publicidad tiende a ofrecer imágenes tradicionales y estereotipadas de hombres y mujeres. Metodológicamente, gran parte de estas investigaciones han optado por aplicar la perspectiva cuantitativa del análisis de contenido siguiendo los planteamientos de trabajos pioneros como el de McArthur y Resko (1975). Como objeto de análisis han considerado, en su mayoría, la publicidad de forma genérica (transmitida a través de un soporte concreto) o aquella relativa a productos tradicionalmente asociados a uno u otro género, como por ejemplo, automóviles o productos de belleza y limpieza (Parkin, 2006: 1).

En nuestra investigación, también aplicamos la técnica cuantitativa del análisis de contenido, pero hemos tomado como objeto de estudio anuncios de televisión relativos a productos de alimentación. Se trata de una publicidad que se ha venido analizando, sobre todo, en relación con el público infantil y los posibles efectos sobre hábitos alimentarios, pero cuyo análisis en referencia a imágenes y roles de género es casi inexistente. Sin embargo, conforma un campo de especial interés ya que, tal y como platean Allen y Sachs: 
"Throughout history, the social relations of food have been organized along lines of gender. Today, in most societies women continue to carry the responsibility for the mental and manual labor of food provision - the most basic labor of care. Women's involvement with food constructs who they are in the world - as individuals, family members and workers" (2007: 1).

\section{Marco teórico}

El estudio de los medios de comunicación desde una perspectiva de género tiene ya una larga tradición (Pearson, 1993; Ross y Byerly, 2004; Byerly y Ross, 2006). Las investigaciones realizadas han analizado el emisor, el contenido de los medios y los receptores; siendo el análisis del contenido mediático el que ha centrado fundamentalmente la atención de los investigadores.

Por lo que respecta a los resultados obtenidos, Gauntlett (2002) diferencia entre los estudios realizados con anterioridad a los años 90 y los desarrollados en esa década y con posterioridad. En los primeros, los resultados son claros en cuanto a la presencia de imágenes estereotipadas de hombres y mujeres, especialmente de éstas últimas. En los 90, Gauntlett afirma que "to a certain extent, programme makers (tv) arrived at comfortable, not-particularlyoffensive models of masculinity and femininity, which a majority of the public seemed to think were OK. Producers thus seemed to give up on feeling that they might need to challenge gender representations" (2002: 65).

Sin embargo, a pesar de la posible percepción de una relativa igualdad, los estudios recientes siguen mostrando la presencia de claros elementos diferenciadores en la forma en que los medios de comunicación representan a hombres y mujeres. Así, y a pesar de la existencia de importantes cambios, destaca la permanencia de una transmisión estereotipada de roles y características, ya sea a través del cine (Gauntlett, 2002), de la prensa y los espacios informativos (Gallego, 2007; Gómez-Escalonilla et al., 2008), de la programación infantil (Baker y Raney, 2007; Espinar, 2007) o de la publicidad, como veremos a continuación.

\subsection{Género y publicidad televisiva}

El estudio pionero de McArthur y Resko (1975) supuso un modelo para investigadores posteriores que han aplicado las técnicas del análisis de contenido a la hora de observar la imagen que la publicidad transmite de hombres y mujeres. Desde estos estudios iniciales, los resultados obtenidos suelen ser coincidentes al señalar la permanencia de estereotipos de género (Furnham y Mak, 1999; Ganahl, Prinsen y Netzley, 2003). Así, tal y como afirman Royo y colaboradores:

"Women have been portrayed in a few narrowly-defined roles as unemployed or as employed in traditional women's occupations such as wife, mother or homemaker [...] They have also been represented as dependent on others, at home and depicted against a background of children $[\ldots]$ in 
decorative roles in relation to the product $[\ldots]$ or as sex objects $[\ldots]$ On the other hand, men have been portrayed as independent, intelligent, hard working, professionals, objective decision-makers $[\ldots]$; as interviewers, narrators, or celebrities [...] and, in other locations different from home" (2008: 381).

Las investigaciones más recientes suelen destacar los cambios que han tenido lugar en las últimas década; aunque siguen planteando la persistencia de ciertos estereotipos (Aronovsky y Furnham, 2008). Tal y como afirman Valls y Martínez, actualmente, "the general opinion is that sexism or gender stereotyping in television advertising continues, although portrayals of women in advertising are becoming more realistic" (2007: 692).

Los cambios observados suponen que "cada vez es mayor la presencia de mujeres en los anuncios emitidos en televisión” (Neto y Silva, 2009:1220); y que éstas aparecen representadas en una mayor diversidad de situaciones: en el ámbito laboral, mostrando productos no domésticos o compartiendo con hombres las responsabilidades domésticas (Aronovsky y Furnham, 2008; Robinson y Hunter, 2008). Sin embargo, estos estudios también destacan que "las mujeres continúan apareciendo, en mayor medida, en contextos domésticos" (Valls y Martínez, 2007: 694-697); "como amas de casa, madres o desempeñando trabajos estereotipados” (Royo, Aldas, Küster y Vila 2008: 381). Físicamente, es más frecuente que aparezcan representadas como "jóvenes adultas, frente a una mayor diversidad, según grupos de edad, a la hora de representar a los caracteres masculinos" (Stern y Mastro, 2004: 216). La presencia de mujeres en los espacios publicitarios sigue siendo inferior a la masculina, sobre todo en la forma de narradores y voces over (Valls y Martínez, 2007; Nassif y Gunter, 2008; Furnham y Farragher, 2001).

Así, los hombres aparecen, en mayor medida como personas autorizadas o expertas, mientras que es más frecuente que las mujeres aparezcan como compradoras o usuarias (Aronovsky y Furnham, 2008). En este sentido, debemos tener presente que el objetivo principal de la publicidad es persuadir la venta de un producto o servicio. Para ello, los publicistas buscan que los productos anunciados se asocien a valores culturales con los cuales el espectador se sienta cómodo. Es decir, para llegar al mayor número de personas y convencer de la adquisición de un producto la publicidad emplea las imágenes "más mayoritarias, que son las más retrógradas y resistentes al cambio" (Santiso, 2001: 46); en definitiva, "definiciones estereotipadas de cómo han de ser hombres y mujeres” (Díaz-Soloaga, 2007: 28).

\subsection{Género en los anuncios de alimentación}

Algunos productos están tradicionalmente ligados a un género en particular. Es precisamente esta publicidad la que ha centrado la atención de gran parte de las investigaciones en el análisis de roles y estereotipos de género (Parkin, 2006); en particular la relativa a productos de belleza o productos de uso doméstico. En líneas generales, para este tipo de publicidad, los resultados muestran que están dirigidos y protagonizados por mujeres, que, frecuentemente, representan roles de género tradicionales (Royo, Aldas, Küster y Vila, 2008). 
Por su parte, los anuncios de alimentos suelen ser considerados "not clearly gender related" (Royo, Aldas, Küster y Vila, 2008: 388) y escasamente han sido objetivo específico de investigación en el análisis de representaciones de género. Esta publicidad se ha analizado, sobre todo, en referencia a la transmisión de hábitos alimentarios, especialmente por lo que respecta al público infantil (Dixon et al., 2007; Sixsmith y Furham, 2009). Así, a pesar de que en todas las sociedades la comida y los procesos a ella ligados (compra, planificación, preparación, etc.) están fuertemente marcados por definiciones de género, apenas se han analizado las representaciones de hombres y mujeres en los anuncios de alimentos.

Para nuestra investigación hemos tomado como trabajos de referencia los realizados por Parkin (2006); Furnham y Li (2008) y Aronovsky y Furnham (2008). Parkin desarrolla, en su libro, un recorrido histórico por la publicidad de alimentos en Estados Unidos. Destaca, así, la persistencia de roles de género tradicionales en este tipo de publicidad a pesar de los cambios sociales experimentados en las últimas décadas en las relaciones de género. En este sentido, el autor subraya que "it is clear that the industry believed they stood to gain from promoting a traditional gender role paradigm". De esta forma, "to reach women, food advertisers moved beyond trumpeting the merits of particular products and suggested that their products would help a woman fulfill her gender roles" (Parkin, 2006: 5-6).

Sin embargo, las premisas a las que llega Parkin no son plenamente coincidentes con los dos estudios empíricos consultados, ambos basados en la aplicación de técnicas cuantitativas de análisis de contenido. De hecho, estos mismos estudios, realizados en contextos geográficos diferentes, llegan a conclusiones contradictorias. Furnham y Li (2008), en su investigación sobre la publicidad de alimentos en Hong Kong, no observan diferencias significativas por razón de género, ni en cuanto a la mera presencia cuantitativa de hombres y mujeres, ni en materia de edad, credibilidad, localización o utilización de argumentos. En concreto, concluyen que "the results confirms there were no significant differences between gender in terms of central figures in the advertisement and this is true across all samples analyzed" (Furnham y Li, 2008: 305).

Utilizando una metodología semejante pero aplicada al caso británico, Aronovsky y Furnham (2008: 181-182) obtienen conclusiones totalmente opuestas: diferencias significativas que indican una mayor presencia femenina; las mujeres son en mayor medida representadas como compradoras o usuarias, mientras que los hombres lo son en mayor medida como autoridades en la materia; es más frecuente que las mujeres representen roles dependientes (esposas, madres); los personajes femeninos aparecen con mayor probabilidad en escenarios domésticos y los hombres en espacios de ocio; finalmente, las mujeres fueron en mayor medida representadas a través de personajes de menor edad que los hombres.

En la investigación que aquí se presenta, tomando como objeto de estudio la publicidad emitida en España en el 2006 y a través del análisis de contenido, pretendemos contrastar nuestros resultados con las conclusiones a las que han llegado tanto los escasos trabajos centrados en el sector de la alimentación como, en general, las investigaciones desarrolladas en torno a la transmisión de contenidos de género a través de la publicidad. 


\section{Planteamiento metodológico}

Tal y como hacen Furnham y Li (2008) y Aronovsky y Furnham (2008) en sus investigaciones sobre la representación de hombres y mujeres en los spots de alimentos, y al igual que gran parte de la investigación empírica realizada en otros sectores publicitarios, en esta investigación también se han empleado técnicas cuantitativas de análisis de contenido (Berelson, 1952). En concreto, a partir de un listado de variables, se ha codificado un total de 407 anuncios con el objetivo de determinar las características asociadas a las figuras masculinas y femeninas que aparecen en ellos. De esta forma, pretendemos contrastar los resultados obtenidos con las investigaciones realizadas con anterioridad, ya sea en referencia al sector de alimentos o a otros sectores publicitarios.

\subsection{Corpus de estudio}

La industria de la alimentación es una de las protagonistas de la publicidad en televisión. Así, según datos de Infoadex ${ }^{1}$, en el año 2006 (año al que corresponden los spots analizados), el sector de la alimentación ocupaba el segundo puesto del ranking en lo referente a inserciones publicitarias en televisión. Para desarrollar esta investigación, dentro del sector de alimentos y siguiendo la clasificación que emplea el propio Infoadex, se han seleccionado los anuncios correspondientes a las 10 categorías con un mayor número de inserciones publicitarias en televisión durante el año $2006^{2}$. De esta forma, se han analizado anuncios relativos a: 1) Alimentos congelados y refrigerados; 2) Cereales; 3) Chocolates; 4) Productos de Cacao; 5) Galletas; 6) Panadería y pastelería; 7) Yogures y postres frescos; 8) Lácteos; 9) Cárnicos; 10) Caramelos y golosinas.

Para cada una de estas diez categorías se ha analizado el total de anuncios existentes: 407 piezas publicitarias. Por lo tanto, hemos tomado como corpus de trabajo, no una muestra sino la población total de spots de las categorías de alimentación seleccionadas; todos ellos anuncios emitidos en las cadenas de televisión nacionales públicas (TVE 1 y La 2) y privadas pero de emisión en abierto (Tele 5, Antena 3, Cuatro y La Sexta) durante el año $2006^{3}$.

\footnotetext{
${ }^{1}$ Información accesible, previa contratación, en: http://www.infoadex.es/ [3/04/ 2011].

${ }^{2}$ Los spots analizados en esta investigación pertenecen al proyecto I+D «Los valores sociales en los spots publicitarios emitidos durante el 2006»(GV06/090), subvencionado por la Generalitat Valenciana y dirigido por la profesora Claudia Rausell.

${ }^{3}$ Cabe señalar que hemos analizado el total de anuncios que Infoadex clasifica en estas diez categorías. Un rasgo común a todos ellos es el hecho de haber sido emitidos durante el 2006 en las cadenas de emisión en abierto en España. Sin embargo, se carece de información referida a las cadenas concretas en las que estos anuncios han sido emitidos, por lo tanto no será posible ningún tipo de análisis comparado entre cadenas.
} 


\subsection{Codificación}

Los resultados que se muestran en este artículo forman parte de una investigación más amplia $^{4}$. De hecho, de las 220 variables que constituyen el estudio general, hemos seleccionado aquellas que permiten realizar un análisis de género; es decir, aquellas que, tomando como unidad de análisis el spot, permiten asociar una serie de rasgos con las voces over y los protagonistas según sean éstos femeninos o masculinos ${ }^{5}$. En concreto, se han estudiado las siguientes características: público objetivo al que se dirige el spot, edad representada por voces over y protagonistas, tipo de reclamo empleado, características estéticas de los personajes protagonistas y espacios donde aparecen.

Sin duda, la codificación de los datos es una de las fases más importantes dentro de la investigación puesto que su correcto registro repercutirá en la calidad de los resultados obtenidos. Para tratar de reducir las posibilidades de error en este proceso se realizó, antes de llevar a cabo el visionado de los spots, un manual de codificación, donde se definieron cada una de las variables empleadas. En concreto, tras una primera determinación de variables, se procedió al visionado y codificación de 50 spots, repartidos de acuerdo a los 10 subcategorías de alimentación objeto de estudio, que conforman, por tanto, el pre-test de esta investigación. A raíz de este visionado, se pudo: a) incorporar cambios en las variables; b) observar incongruencias entre las variables; c) elaborar el manual de codificación definitivo.

Finalmente, se diseñó una plantilla en el entorno del programa estadístico SPSS, que facilitara el visionado y codificación de la información. En este sentido, ambas autoras codificaron los anuncios seleccionados a partir de las variables que se consideraron pertinentes para un análisis de género. El nivel de acuerdo alcanzado entre las codificadoras es del 92\%; los desacuerdos se resolvieron a través de discusión y consenso (Gentry y Harrison, 2010: 84).

\section{Resultados y análisis}

Algunos estudios, por ejemplo aquellos que han estudiado con anterioridad la imagen de hombres y mujeres en los spots de alimentación (Furham y Li, 2008; Aronvosky y Furham, 2008), analizan, conjuntamente, voces over y protagonistas como caracteres principales. Nosotras, sin embargo, hemos optado por considerar de forma separada los rasgos asociados a personajes protagonistas6 de los asociados a voces over, buscando, cuando es posible, la comparación entre ambos tipos de caracteres. En concreto, se han analizado las características

\footnotetext{
${ }^{4}$ En concreto, forma parte del proyecto de Tesis Doctoral de la profesora Cristina González Díaz, titulado "Análisis de la forma y el contenido de los spots de alimentación dirigidos a la infancia" defendido en el 2011.

${ }^{5}$ Tal y como hacen en sus investigaciones Furnham y Li (2008) y Aronovsky y Furnham (2008).

${ }^{6}$ En esta investigación hemos considerado personajes protagonistas a todos aquéllos que tenían un peso relevante (latente o manifiesto) en el desarrollo de la pieza publicitaria, siendo los mismos el eje de la trama sobre el que se desarrolla el mensaje publicitario.
} 
de la voz over principal $^{7}$ de cada spot, en el caso de que apareciera alguna, y de hasta cinco protagonistas por anuncio ${ }^{8}$.

Finalmente, en el $88 \%$ de los spots seleccionados se emplea alguna variedad de voz over; mientras que en el $93 \%$ se muestra, como mínimo, un protagonista. Son, por tanto, estos anuncios los que constituyen nuestro corpus final de estudio. En la tabla 1 puede observarse cómo se distribuyen, según género, el total de voces over y protagonistas. Así, mientras que la presencia de protagonistas es prácticamente equilibrada (con un $53 \%$ de protagonistas femeninos y un $47 \%$ de protagonistas masculinos), el desequilibro es obvio en el caso de las voces over, que son mayoritariamente masculinas (un $71 \%$, frente al $29 \%$ de voces over femeninas). Es decir, si bien físicamente la presencia de personajes femeninos es elevada (incluso más elevada que la masculina), los spots de alimentación parecen optar, de forma predominante, por voces masculinas a la hora de ofertar los distintos productos.

Tabla 1: Voces over y protagonistas según género

\begin{tabular}{|c|c|c|c|}
\cline { 3 - 4 } \multicolumn{2}{c|}{} & Voces over & Protagonistas \\
\hline \multirow{2}{*}{ Género } & Femenino & $29 \%$ & $53 \%$ \\
\cline { 2 - 4 } & Masculino & $71 \%$ & $47 \%$ \\
\hline \multicolumn{2}{|c|}{ Total } & $100 \%$ & $100 \%$ \\
\hline \multicolumn{2}{|c}{ Elaboración propia }
\end{tabular}

Coincidimos, así, con estudios empíricos previos (Rausell, González y Ortiz, 2008; Valls y Martínez, 2007; Nassif y Gunter, 2008; Whippe y McManamon, 2002) que sitúan la mayor desigualdad en cuanto a presencia de hombres y mujeres en aquella que toma la forma de narradores y voces over. Más difícil es contrastar los resultados obtenidos con los centrados en los spots de alimentación (Furnham y Li, 2008 y Aronovsky y Furnham, 2008); ya que no diferencian entre voces over y protagonistas, analizando ambos caracteres de forma conjunta. Ello puede explicar que los resultados difieran de los obtenidos en nuestro estudio, ya que estos autores o no encuentran diferencias cuantitativas entre géneros o, en el caso británico, las diferencias hablan de una mayor presencia femenina.

De acuerdo a investigaciones previas (Aronovsky y Furnham, 2008:172), en la publicidad es más frecuente la utilización de voces masculinas debido a la connotación de

\footnotetext{
${ }^{7}$ En esta investigación entenderemos como voz over aquéllas que se instalan en paralelo a las imágenes emergiendo como una fuente exterior a los elementos que intervienen diegéticamente en la pieza publicitaria. Es el caso de las voces de los narradores. Lo común es la presencia de una sola voz over, pero en esta investigación se ha partido del estudio de hasta un máximo de 3. Sin embargo, hemos de puntualizar mientras un $87.06 \%$ de los spots analizados contaban con un única voz over; tan sólo el $3,93 \%$ tenía dos oves over; y en ningún spot de los analizados se ha encontrado tres voces over.

${ }^{8} \mathrm{Se}$ ha estudiado hasta un máximo de 5 protagonistas. Los resultados ponen de manifiesto como la generalidad es la presencia de uno o dos personajes principales, ya que se ha observado la práctica ausencia de protagonistas 3, 4 o 5 (un 75,92\% de los spots no poseían protagonista 3; un 87,71\% de los spots no contaban con protagonista 4 ; y un $94,59 \%$ de las piezas analizadas no tenía protagonista 5).
} 
credibilidad y autoridad que el hombre posee sobre la mujer de cara a exponer los beneficios del producto. Sin embargo, tal y como apuntan Whipple y McManamon (2002:81), no hay investigaciones que evidencien la efectividad real de la voz masculina frente a la femenina; por lo que la supremacía de la primera sobre la segunda, responde a supuestos no sujetos a ningún tipo de fundamentación científica que permita afirmar que un locutor masculino tiene más capacidad de influencia en el target que una voz over femenina.

En este sentido, podemos aportar más información si, a la hora de analizar la presencia de caracteres masculinos y femeninos, atendemos al público objetivo de los spots en los que aparecen. Tal y como puede observarse en la tabla 2, en todos los casos, las voces over son predominantemente masculinas. Sin embargo, este predominio es especialmente elevado en el caso de la publicidad dirigida a niños, donde alcanza el 92,6 \% de las voces over empleadas; mientras que, cuando la publicidad se dirige a adultos, se incrementa la presencia de voces over femeninas (que representan el 39,3\% de las voces over dirigidas a este público). Es decir, es a los adultos a los que, en mayor grado, se les intenta convencer con voces femeninas; mientras que al dirigirse al público infantil se opta, unánimemente, por voces masculinas. Esta relación entre género de la voz over y público objetivo puede calificarse de estadísticamente significativa según los valores del Chi-cuadrado asociado.

Tabla 2: Público objetivo por género de la voz over y del protagonista

\begin{tabular}{|c|c|c|c|c|}
\cline { 3 - 4 } \multicolumn{2}{c|}{} & \multicolumn{3}{c|}{ Público objetivo $^{\mathbf{9}}$} \\
\cline { 3 - 5 } & Femenina & Niños & Adultos & Ambos \\
\hline \multirow{3}{*}{ Voz over $^{10}$} & Masculina & $9,4 \%$ & $39,3 \%$ & $28,6 \%$ \\
\cline { 2 - 5 } & Total & $100 \%$ & $60,7 \%$ & $71,4 \%$ \\
\cline { 2 - 5 } & Femenino & $29,0 \%$ & $63,5 \%$ & $100 \%$ \\
\hline \multirow{3}{*}{ Protagonista $^{11}$} & Masculino & $71,0 \%$ & $36,5 \%$ & $53,8 \%$ \\
\cline { 2 - 5 } & Total & $100 \%$ & $100 \%$ & $100 \%$ \\
\cline { 2 - 5 } & & & \\
\hline
\end{tabular}

Elaboración propia

Por lo que respecta a la presencia de personajes (consultar nuevamente la tabla 2), la distribución muestra mayores desequilibrios que cuando considerábamos el conjunto de

\footnotetext{
${ }^{9}$ Dentro de las variables de control que conformaban la plantilla de datos, se incluyó el público destinatario de los spots, diferenciando según si fueran exclusivamente niños, exclusivamente adultos o si se trataba de publicidad cuya estrategia comunicativa abarcaba a ambos públicos.

${ }^{10}$ Los datos relativos a la voz over corresponden a la tabla de contingencia realizada entre las variables el público al que se dirige el spot y género de la voz over. Chi-cuadrado significativo $(\mathrm{P}=0,001, \chi 2=$ $35,666)$.

${ }^{11}$ La información referida a protagonistas corresponde a la tabla de contingencia para variables de respuesta múltiple según género del protagonista y público objetivo. Los porcentajes están basados sobre el total de respuestas; en nuestro caso, eso supone que los porcentajes están calculados a partir del total de protagonistas destinados a cada categoría de grupo objetivo.
} 
protagonistas sin atender al público objetivo (tabla 1). Así, si los spots se dirigen a niños destaca la presencia mayoritaria de protagonistas masculinos (un $71 \%$ de estos protagonistas). Sin embargo, cuando el spot se dirige a adultos, los protagonistas son principalmente femeninos (en un 63,5\%). Es decir, tanto voces over como protagonistas masculinos aparecen en mayor medida cuando la publicidad se dirige a un público infantil; mientras que cuando la publicidad se dirige a un público adulto los protagonistas son principalmente mujeres y, aunque las voces masculinas sigan siendo las dominantes, la presencia de femeninas es mayor que en el caso de otros públicos. De esta forma, a diferencia de lo que tradicionalmente suele plantearse, podemos concluir que no es sólo credibilidad o autoridad lo que parecen aportar las voces o los protagonistas masculinos sino que, especialmente, se observan como más capaces de conectar con el público infantil, por lo menos en el caso concreto de la publicidad de alimentos.

Además de la mera presencia de voces y protagonistas de uno u otro género, las variables construidas nos permiten relacionarlos con diferentes características; como, por ejemplo, el tipo de reclamo empleado a la hora de presentar el producto. En este sentido, y previo a la incorporación de la variable género, destaca el uso de cuatro categorías de reclamo: el carácter saludable del producto (que aparece en un 36,1\% de los spots analizados); su capacidad para ayudar a mantener la línea (en un 21,1 \% de los spots); su relación con promociones o descuentos (en un 19,4\%); y su presentación como algo novedoso o exclusivo (en un 8,1\%). En concreto, la alta presencia de los dos primeros reclamos parecen dar la razón a Furnham y Li (2008:298), quienes afirman que, dado que la publicidad de alimentos se dirige especialmente a las mujeres (principales responsables de la compra y preparación de alimentos), tiende a apelar a lo que son consideradas supuestas preocupaciones femeninas, como son la salud y la imagen.

Respecto a la relación entre el género de voces over y protagonistas y los reclamos empleados, pueden consultarse los resultados en la tabla 3. Así, aunque las diferencias por género son mínimas a la hora de ofertar el producto o alguno de sus elementos como novedoso o exclusivo (aparecen ligados a este reclamo el 30,4\% de las voces over femeninas y el $27,8 \%$ de las masculinas; así como el 26,2\% de las protagonistas y el 23,4\% de los protagonistas masculinos), éstas son claras por lo que respecta a los otros tres reclamos empleados con mayor frecuencia. De esta forma, las mujeres aparecen en mayor grado asociadas al carácter saludable del producto (un 36,3\% de las voces over femeninas frente al 29,0\% de las masculinas; y un $35,1 \%$ de las protagonistas frente el $25,4 \%$ de los protagonistas) y, sobre todo, a la ayuda que éste puede suponer a la hora de mantener un cuerpo delgado. En concreto, esta referencia estética no se trata sólo de un reclamo supuestamente dirigido a mujeres sino también presentado por mujeres (en concreto, por un 18,6\% de las voces over femeninas y un 10,1\% de las protagonistas; frente al 2,0\% de las voces over masculinas y el 2,5\% de los protagonistas).

Por otra parte, las diferencias son también claras en lo que respecta a la asociación del producto con promociones y descuentos. Así, esta categoría es más frecuente entre los caracteres masculinos: un 23,9\% de las voces over masculinas frente a sólo el 4,9 \% de las 
femeninas, y un $27,7 \%$ de los protagonistas masculinos frente al $14,7 \%$ de las protagonistas femeninas. Finalmente, aunque con cifras mucho menores, también es mayor el porcentaje de caracteres masculinos relacionados con la diversión como forma de venta del producto, sobre todo en referencia a los protagonistas, que alcanzan un $8,6 \%$ frente al $3,7 \%$ de las protagonistas femeninas.

Tabla 3: Tipo de reclamo por género de la voz over y del protagonista

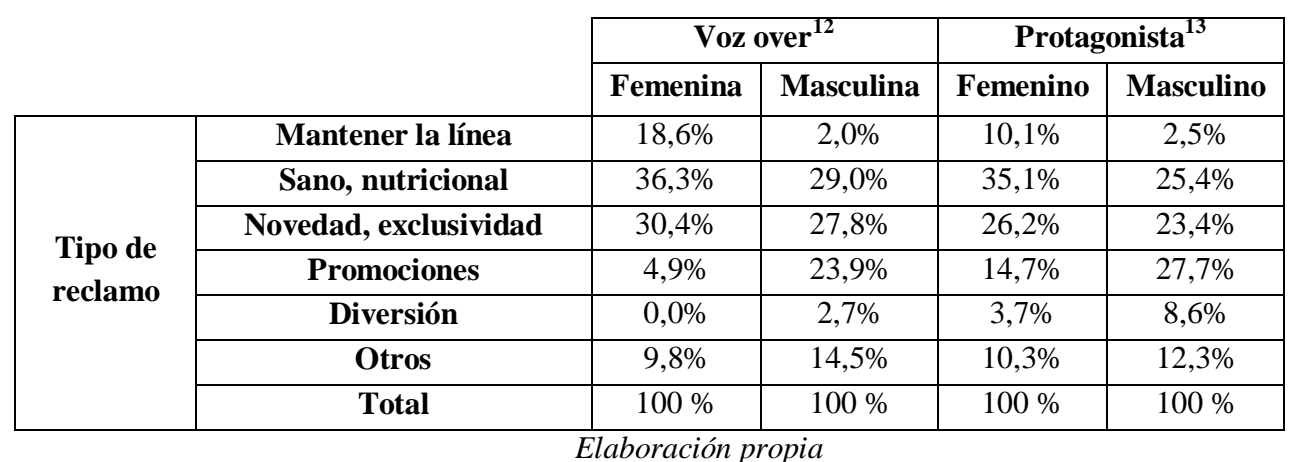

Junto a los reclamos empleados, también se han analizado otras características asociadas a los caracteres masculinos y femeninos. En concreto, tanto para voces como para protagonistas se ha codificado la edad; mientras que la presencia física de los protagonistas ha permitido observar tanto su apariencia estética como el espacio en el que aparecen ubicados.

De este modo, en la tabla 4 puede observarse cómo las voces over empleadas son, casi exclusivamente, adultas. La voz infantil está prácticamente ausente; no hay voces infantiles masculinas y sólo suponen un 9,4 \% de las voces over femeninas. Sin embargo, la situación cambia en el caso de los protagonistas, cuya presencia física permite un mayor nivel de detalle a la hora de considerar el grupo de edad representado. En concreto, gran parte de los protagonistas se sitúan en dos categorías: menores y jóvenes; si bien con diferencias entre hombres y mujeres. Así, mientras un 57,7 \% de los protagonistas masculinos y un 31,9\% de las protagonistas femeninas son menores; los porcentajes se invierten en el caso de los jóvenes, categoría en la que se sitúa un $32 \%$ de los protagonistas masculinos y un $52,6 \%$ de las femeninas. La presencia de protagonistas adultos es mucho menor (un 12,4\% de las mujeres protagonistas y un 5,5\% de los hombres) y prácticamente inexistente la de personajes que puedan ubicarse en la tercera edad.

\footnotetext{
${ }^{12}$ Los datos relativos a la voz over corresponden a la tabla de contingencia realizada entre las variables reclamo publicitario y género de la voz over. Chi-cuadrado significativo $\left(\mathrm{P}=0,001, \chi^{2}=49,785\right)$.

${ }^{13} \mathrm{La}$ información referida a protagonistas corresponde a la tabla de contingencia para variables de respuesta múltiple según género del protagonista y tipo de reclamo. Los porcentajes están basados sobre el total de respuestas; en nuestro caso, eso supone que los porcentajes están calculados a partir del total de protagonistas empleados, diferenciados según género.
} 
Tabla 4: Edad representada por las voces over y los protagonistas según género

\begin{tabular}{|c|c|c|c|}
\hline & & \multicolumn{2}{|c|}{ Voz over $1^{14}$} \\
\hline & & Masculina & Femenina \\
\hline \multirow{3}{*}{ Edad } & Menor & $0 \%$ & $9,4 \%$ \\
\hline & Adulto & $100 \%$ & $90,6 \%$ \\
\hline & Total & $100 \%$ & $100 \%$ \\
\hline & & \multicolumn{2}{|c|}{ Protagonista $^{15}$} \\
\hline & & Masculino & Femenino \\
\hline \multirow{6}{*}{ Edad } & Menor (menos de 18) & $57,7 \%$ & $31,9 \%$ \\
\hline & Joven y adulto joven (18 a 30) & $32,0 \%$ & $52,6 \%$ \\
\hline & Adulto (41 a 64 años) & $5,5 \%$ & $12,4 \%$ \\
\hline & Tercera Edad (65 o más) & $1,8 \%$ & $1,7 \%$ \\
\hline & No específica. & $3,0 \%$ & $1,4 \%$ \\
\hline & Total & $100 \%$ & $100 \%$ \\
\hline
\end{tabular}

Elaboración propia

Estos resultados están en consonancia con estudios previos que observan una tendencia a concentrar la presencia de mujeres en la forma de jóvenes adultas (Stern y Mastro, 2004: 216). Sin embargo, de acuerdo a nuestros datos, la diversidad de grupos de edad representados es limitada tanto para hombres como para mujeres, que son mayoritariamente caracterizados como jóvenes o como menores, con escasa presencia de otros grupos. En este sentido, mientras estudios anteriores (Götz, et al.,2008:8) señalan la ausencia de mujeres de avanzada edad en la publicidad; de acuerdo a nuestros resultados podemos hablar de una ausencia generalizada de protagonistas de este grupo etario, ya sean hombres o mujeres. Prosiguiendo con el análisis, y tal y como planteábamos anteriormente, la presencia de personajes en los spots permite analizar otras característica adicionales, como su aspecto físico y el espacio en el que son ubicados. Así, por lo que respecta a la apariencia, se ha clasificado a los protagonistas en tres posibles categorías: feos, guapos y normales (ver tabla 5). Han sido codificados como «feos» aquellos protagonistas que fundamentan su presencia en la representación explícita de rasgos ajenos a los cánones de belleza dominantes (gordura, extrema delgadez masculina, descuido estético, etc.); «guapos» son aquellos que se convierten en el elemento central del anuncio a partir de la exposición de rostros y cuerpos ligados a los cánones dominantes, fundamentalmente, en el mundo de la moda. El resto de protagonistas, es decir aquellos que no son claramente clasificables como «feos» o «guapos» han sido codificados en la categoría de «normales». Por otra parte, para confeccionar esta variable, las investigadoras se han basado en trabajos anteriores que abordaban el estudio de esta temática (Martín Llaguno, 2002; Carrillo, 2003; Jiménez, 2008; Muela, 2008).

\footnotetext{
${ }^{14}$ Los datos relativos a la voz over corresponden a la tabla de contingencia realizada entre las variables género y edad de la voz over. Chi-cuadrado significativo $(\mathrm{P}=0,001, \chi 2=10,292)$.

${ }^{15} \mathrm{La}$ información referida a protagonistas corresponde a la tabla de contingencia para variables de respuesta múltiple según género y edad del protagonista. Los porcentajes están basados sobre el total de respuestas; en nuestro caso, eso supone que los porcentajes están calculados a partir del total de protagonistas empleados, diferenciados según género.
} 
Tabla 5: Belleza del protagonista según género

\begin{tabular}{|c|c|c|c|}
\hline & & \multicolumn{2}{|c|}{ Género $^{16}$} \\
\hline & & Femenino & Masculino \\
\hline \multirow{5}{*}{ Apariencia estética } & Feo & $1,7 \%$ & $5,8 \%$ \\
\hline & Normal & $52,0 \%$ & $51,8 \%$ \\
\hline & Guapo & $44,3 \%$ & $24,9 \%$ \\
\hline & No explícito & $2,0 \%$ & $17,5 \%$ \\
\hline & Total & $100 \%$ & $100 \%$ \\
\hline
\end{tabular}

Elaboración propia

Tanto para personajes masculinos como femeninos, la presencia de «feos» es mínima, aunque algo más elevada en el caso de los protagonistas masculinos (un 5,8 \% frente al 1,7 \% de los personajes femeninos). Los mayores porcentajes se sitúan entre los que hemos considerado personajes «normales»; en torno al $52 \%$ tanto para hombres como para mujeres. Estos resultados parecen mostrar, en el caso concreto de la publicidad de alimentos, las preferencias de los anunciantes por emplear modelos relativamente cercanos, desde el punto de vista estético, al futuro consumidor.

Por otra parte, también encontramos una elevada presencia de protagonistas que pueden considerarse guapos. Esta presencia es especialmente alta en el caso de las mujeres, que en un 44,3\% se sitúan en esta categoría (en el caso de los hombres, el porcentaje desciende hasta el $24,9 \%$ ). De esta forma, la presencia de modelos que rayan la perfección estética sigue siendo elevada, sobre todo cuando se trata de mujeres.

Finalmente, otro rasgo frecuentemente analizado en estudios anteriores (Furnham y Li, 2008; Aronovsky y Furnham, 2008) es el espacio en el que se sitúa la acción de los personajes. En nuestro caso, tal y como puede observarse en la tabla 6, la mayor parte de los personajes se sitúan o en un espacio doméstico o exterior.

En concreto, las mujeres aparecen en mayor medida en espacios domésticos (un 48,8\% de las protagonistas) en comparación con los hombres (un 35,2\% de los personajes masculinos); mientras que en menor grado se sitúan en espacios exteriores (un 24,7 \% de las protagonistas frente al 34,5\% de los protagonistas). Estos resultados coinciden con los obtenidos en investigaciones previas (Valls y Martínez, 2007; Bresnahan, Inoue, Liu y Nishida, 2001).

\footnotetext{
${ }^{16}$ Los datos corresponden a la tabla de contingencia para variables de respuesta múltiple según género y apariencia estética del protagonista. Porcentajes basados sobre el total de las respuestas; en nuestro caso, eso supone que los porcentajes están calculados a partir del total de protagonistas presentes en los spots, diferenciados según género.
} 
Tabla 6: Ubicación según género del protagonista

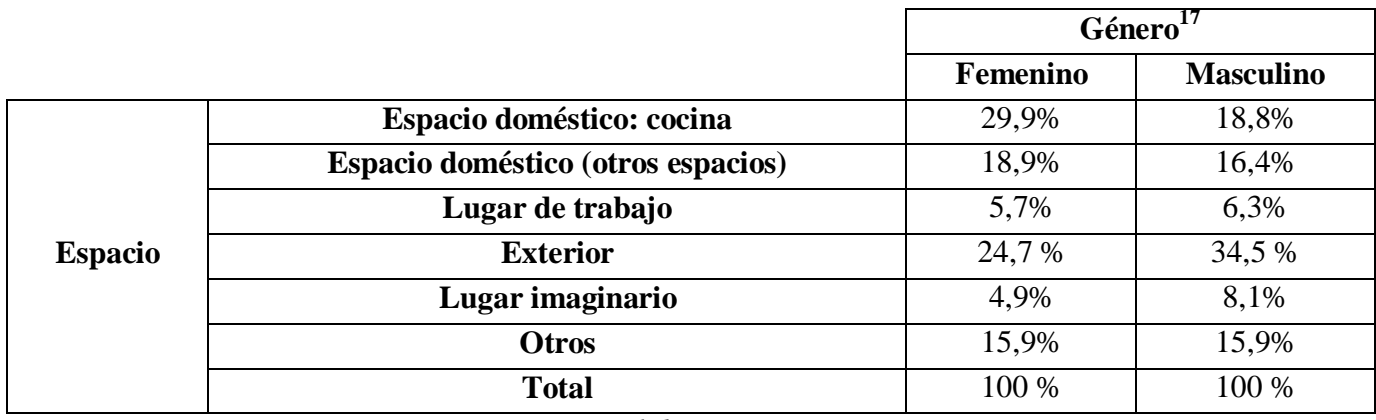

Elaboración propia

Como puede apreciarse en la tabla 6, a la hora de codificar los anuncios, se ha distinguido según si la acción tenía lugar en la cocina o en otros espacios domésticos. Tal diferenciación ha permitido observar que los protagonistas masculinos y femeninos son ubicados en porcentajes similares en espacios domésticos diferentes a la cocina (un 18,9\% de las mujeres y un $16,4 \%$ de los hombres), mientras que, cuando el espacio representado es una cocina, las desigualdades son claras. Así, en este contexto, se sitúa en torno al $30 \%$ de los personajes femeninos y al $19 \%$ de los masculinos. Estos datos parecen respaldar las conclusiones de otros autores (Coltrane y Messineo, 2000; Royo, Aldas, Küster y Vila, 2008) que plantean la permanencia, en los contenidos publicitarios, de roles de género tradicionales que caracterizan a la mujer como la responsable (y experta) del cuidado y atención de los distintos miembros de la familia.

\section{Conclusiones}

Los resultados obtenidos presentan considerables diferencias respecto a los aportados por los estudios empíricos previos sobre publicidad en el sector de la alimentación. Así, cabe recordar que, analizando conjuntamente voces over y protagonistas, Furnham y Li (2008) planteaban una presencia equilibrada de caracteres femeninos y masculinos; mientras que Aronovsky y Furnham (2008) destacaban una mayor presencia femenina. A diferencia de estas investigaciones, en nuestro estudio analizamos de forma separada voces over y protagonistas; así, los datos muestran una mayor presencia de voces over masculinas y una distribución

\footnotetext{
${ }^{17}$ Los datos corresponden a la tabla de contingencia para variables de respuesta múltiple según género del protagonista y espacio donde se desarrolla la acción principal del spot. Porcentajes basados en el total de las respuestas; en nuestro caso, eso supone que los porcentajes están calculados a partir del total de protagonistas presentes en los spots, diferenciados según género.
} 
relativamente equilibrada por lo que respecta a los protagonistas. Estos resultados están en consonancia con los aportados por investigaciones previas sobre muestras generales de publicidad televisiva, que destacan tanto la creciente presencia femenina en la publicidad (Neto y Silva, 2009) como el persistente protagonismo masculino entre las voces over (Valls y Martínez, 2007; Nassif y Gunter, 2008; Furnham y Farragher, 2001).

Tradicionalmente, la mayor presencia de narradores masculinos se ha relacionado con supuestas connotaciones de credibilidad y autoridad asociadas a la voz masculina. Sin embargo, (Whipple y McManamon, 2002: 80-81) señalan que esta creencia en una mayor efectividad de la voz masculina frente a la femenina no está fundamentada en criterios científicos sino en meras suposiciones. En este sentido, de acuerdo a los resultados obtenidos, ciertamente parece que a la hora de diseñar un mensaje publicitario el hecho de optar por un narrador masculino no sólo se basa en la búsqueda de credibilidad o confianza. Así, cuando la publicidad se orienta a un público infantil se emplean casi de forma unánime voces over masculinas; sin embargo, cuando el target es adulto, aunque el mayor porcentaje siga correspondiendo a las voces masculinas, la presencia de femeninas se eleva considerablemente. Igualmente, si tenemos en cuenta los reclamos empleados; las voces over femeninas se asocian, en mayor medida, con reclamos que tratan de explicar los beneficios que el consumo del producto reporta en la salud y en el cuidado estético del cuerpo; mientras que las voces masculinas guardan una mayor relación con promociones, descuentos o la diversión como reclamo. En definitiva, las voces over masculinas están especialmente asociadas al público infantil y a reclamos emocionales no directamente asociados con la explicación de los beneficios del producto.

Por otro lado, independientemente del género de voces y protagonistas, los reclamos que se emplean con mayor frecuencia son los referentes a la naturaleza saludable del producto y a sus aportaciones a la hora de mantener un cuerpo delgado. En este sentido, coincidimos con autores previos (Furnham y Li, 2008:298) que destacan la presencia de este tipo de mensajes en los anuncios de alimentos; mensajes que suelen asociarse con intereses supuestamente femeninos y que responderían a la consideración de las mujeres como las principales destinatarias de la publicidad de alimentación. Es más, no se trata, sólo, de reclamos dirigidos a mujeres sino también transmitidos por caracteres femeninos; ya que los porcentajes de voces over y protagonistas femeninos asociados a la salud y al efecto estético del producto como reclamos son considerablemente mayores que los porcentajes masculinos.

Además, las mujeres representadas no sólo protagonizan en mayor medida reclamos relacionados con el cuidado estético, sino que claramente son en mayor grado atractivas en comparación con los personajes masculinos. Así, aunque la presencia de protagonistas «normales» es elevada, tanto para hombres como para mujeres; las diferencias son claras por lo que respecta a la belleza estética, siendo mucho más usual cuando los actores son mujeres que 
cuando son hombres. En esta misma línea se sitúan gran parte de las investigaciones previas desarrolladas, permitiendo concluir que, en el caso de las mujeres, "exaggerated beauty standards are the norm in television commercials" (Stern y Mastro, 2004: 219).

En cuanto a la edad de los protagonistas, nuestros datos difieren, en ciertos aspectos, de los usualmente obtenidos en el análisis de la publicidad. Así, la escasa variedad de grupos de edad representada por las mujeres que señalan algunos estudios (Stern y Mastro, 2004: 216), afecta igualmente a los hombres; de forma que la mayor parte de los protagonistas son o jóvenes o menores. Sin embargo, las diferencias por género también son claras, apareciendo en mayor medida las mujeres como jóvenes adultas (en coherencia con lo visto por Larson, $2001 \mathrm{o}$ Fullerton y Kendrick, 2000) y los hombres como niños. La presencia de actores de edad avanzada es inexistente, tanto para hombres como para mujeres.

Finalmente, los resultados obtenidos también nos permiten hablar de diferencias de género en referencia a la ubicación de los personajes. Así, tal y como plantean estudios previos (Valls, y Martínez, 2007: 694-697), los protagonistas masculinos aparecen en mayor medida en espacios exteriores mientras que es más frecuente que los femeninos se sitúen en espacios domésticos. En concreto, es claramente mayor el porcentaje de protagonistas femeninas ubicadas en la cocina, en comparación con la presencia de protagonistas masculinos en dicho espacio. De esta forma, los datos coinciden con los resultados obtenidos por Aronovsky y Furnham (2008), frente a Furnham y Li (2008), que no observaban diferencias significativas en esta dimensión.

Así pues, considerando los estudios previos en el campo concreto de la publicidad de alimentos, nuestros resultados se sitúan relativamente cercanos a los aportados por Aronovsky y Furnham (2008), permitiendo señalar la existencia de diferencias claras en los contenidos de género que transmite esta publicidad, tanto en cuanto a la presencia cuantitativa de caracteres, como con respecto a los reclamos empleados, las características estéticas, la edad o el espacio en el que se sitúa la acción de los protagonistas.

En definitiva, estos datos constatan que la publicidad, como reflejo social y transmisora de valores, está mostrando, no sólo mediante sus protagonistas, sino también mediante sus narradores y el reclamo publicitario, patrones e imágenes estereotipadas de hombres y mujeres. Así, aunque la publicidad ha ido incorporando elementos acordes con los cambios sociales acaecidos en las últimas décadas, sigue optando, en gran medida, por el empleo de rasgos tradicionales a la hora de ofertar sus productos. De esta forma, el análisis de los contenidos publicitarios permite, por un lado, poner en duda sus aportaciones en términos de cambio social; a la vez que, como supuesto reflejo de deseos e identidades, se convierte en una prueba más de la permanencia de rasgos tradicionales y estereotipados de género en el contexto social que le sirve de marco. 


\section{Bibliografía}

- Allen, Patricia y Sachs, Carolyne (2007): "Women and Food Chains: The Gendered Politics of Food". En International Journal of Sociology of Food and Agriculture, Vol. 15, n 1, pp. 1-23.

- Aronovsky, Alexandra y Furnham, Adrian (2008): "Gender portrayals in food commercials at different times of the day: A content analytic study”. En Communications, $\mathrm{n}^{\mathbf{0}} 33$, pp. 169-190.

- Baker, Kaysee y Raney, Arthur (2007): "Equally super? Gender-role stereotyping of superheroes in children's animated programs". En Mass Communication \& Society, Vol. $10, \mathrm{n}^{\mathrm{o}} 1$, pp. $25-41$.

- Bandura, Albert (1994): "Social cognitive theory of mass communication". En Jenings Bryant y Dolf Zillmann (eds.): Media effects: Advances in theory and research. Hillsdale, NJ, Lawrence Erlbaum Associates, pp. 61-90.

- Berelson, Bernard (1952): Content analysis in Communication Research. Glencoe, Ill: The Free Press.

- Bresnahan, Mary; Inoue, Yasuhiro; Liu, Wen Y. y Nishida, Tsukasa (2001): "Changing gender roles in prime-time commercials in Malaysia, Japan, Taiwan, and the United States". En Sex Roles, no 45, pp. 117-131.

- Byerly, Carolyne y Ross, Kate (2006): Women and Media. A critical Introduction. Maryland: Blackwell.

- Coltrane, Scott y Messineo, Melinda (2000): “The perpetuation of subtle prejudice: Race and gender imagery in 1990s television advertising”. En Sex Roles, n 42, pp. 363-389.

- Díaz Soloaga, Paloma (2007): "Valores y estereotipos femeninos creados en la publicidad gráfica de las marcas de moda de lujo en España”. En Anàlisi, n 35, pp. 27-45.

- Dixon, Harold et al. (2007): "The effects of television advertisements for junk food versus nutritious food on children's good attitudes and preferences". En Social Science and Medicine, $\mathrm{n}^{\mathrm{o}}$ 65, pp. 1311-1323.

- Espinar, Eva (2007): "Estereotipos de género en los contenidos audiovisuales infantiles". En Comunicar, $\mathrm{n}^{\circ} 29$, pp. 129-134.

- Fullerton, Jamie y Kendrick, Alice (2000): "Portrayal of men and women in U.S. Spanishlanguage television commercials". En Journalism \& Mass Communication Quarterly, Vol. $77, \mathrm{n}^{\circ} 1$, pp. 128-142.

- Furnham, Adrian y Farragher, Elena (2001): “A cross-cultural content analysis of sex-role stereotyping in television advertisements: A comparison between Great Britain and New Zealand”. En Journal of Broadcasting and Electronic Media, n 44, pp. 415-436. 
- Furnham, Adrian y Li, Jessica (2008): "Gender portrayal in food and beverage advertisements in Hong Kong: a content analytic study”. En, Young consumers, Vol. 9, n ${ }^{\circ}$ 4, pp. 297-307.

- Furnham, A y Mak, Twiggy (1999): "Sex-role stereotyping in television commercials: A review and comparison of fourteen studies done on five continents over 25 years". En Sex Roles, $\mathrm{n}^{\circ}$ 41, pp. 413-437.

- Gallego, Juana (2007): “Lenguaje periodístico y discriminación de género". En Juan F. Plaza y Carmen Delgado (eds.): Género y comunicación, Madrid, Fundamentos, pp. 49-72.

- Ganahl, Dennis J.; Prinsen, Thomas J. y Netzley Sara B. (2003): “A content analysis of prime time commercials: A contextual framework of gender representation". En Sex Roles, no 49 , pp. 545-551.

- Gauntlett, David (2008) [2002]: Media, Gender and Identity. An introduction. Londres y Nueva York: Routledge.

- Gentry, James y Harrison, Robert (2010): "Is advertising a barrier to male movement toward gender change?”. En Marketing Theory, Vol. 10, nº 1, pp. 74-96.

- Goffman, Erving (1979): Gender Avertisements. Londres: Macmillan.

- Gómez-Escalonilla, Gloria et al. (2008): "La imagen de la mujer política en los medios de comunicación”. En Feminismo/s, nº 11, pp. 59-71.

- Götz, Maya et al. (2008): "Gender in children's television worldwide. Results from a media analysis in 24 countries”. En Televizion, n 21, pp. 4-9.

- Kilbourne, Jean (1999): Deadly persuasion: Why women and girls must fight the addictive power of advertising. Nueva York: The Free Press.

- Jiménez, Mónika (2008): "El Glamour como excusa: los trastornos del comportamiento alimentario en la prensa española”. En Trastornos de la Conducta Alimentaria, n 7, pp. 767-785.

- Larson, Mary (2001): "Interactions, activities and gender in children's television commercials: A content analysis". En Journal of Broadcasting and Electronic Media, $\mathrm{n}^{\mathrm{o}}$ 45, pp. 41-65.

- Martín Llaguno, Marta (2002): "La tiranía de la apariencia en la sociedad de las representaciones". En Revista Latina de Comunicación Social, $\mathrm{n}^{\circ}$ 50, [en línea] Disponible en: http://www.ull.es/publicaciones/latina/2002/latina50mayo/5005mllaguno.htm [31/01/2012].

- Martín Serrano, Manuel (2004): La producción social de la comunicación. Madrid: Alianza.

- Nassif, Atif y Gunter, Barrie (2008): “Gender Representation in Television Advertisements in Britain and Saudi Arabia”. En Sex Roles, n 58, pp. 752-760. 
- Neto, Félix y Silva, Carolina (2009): "Changing Patterns of Gender Portrayals in Portuguese Television Advertisements”. En Journal of Applied Social Psychology, Vol. 39, $\mathrm{n}^{\mathrm{o}} 5$, pp. 1214-1228.

- Parkin, Kate (2006): Food is love. Advertising and Gender Roles in Modern America. Philadelphia: Pennsylvania, University of Pennsylvania Press.

- Pearson, Joel (ed.) (1993): Comunicación y género. Barcelona: Paidós.

- Peña, Cristina y Frabetti, Carlo (1990): La mujer en la publicidad. Madrid: Instituto de la Mujer.

- Rausell, Claudia; Gónzalez, Cristina y Ortiz, Mª Jesús (2008): “Características de la figura humana en los spots de bebidas emitidos en España en 2006”. En Revista Latina de Comunicación Social, $\mathrm{n}^{\circ}$ 63, pp. 220-223.

- Robinson, Brian y Hunter, Erika (2008): “Is Mom Still Doing It All? Reexamining Depictions of Family Work in Popular Advertising". En Journal of Family Issues, Vol. 29, no 4, pp. 465-486.

- Ross, Karen y Byerly, Carolyn (2004): Woman and media: international perspective. Maryland: Blackwell.

- Royo, Martín; Aldas, Joaquin; Küster, Inés y Vila, Natalia (2008): “Adaptation of Marketing Activities to Cultural and Social Context: Gender Role Portrayals and Sexism in Spanish Commercials". En Sex Roles, n 58 , pp. 379-390.

- Santiso, Raquel (2001): "Las mujeres en la publicidad: análisis, legislación y aportaciones para un cambio". En Acciones e Investigaciones Sociales, n 13, pp. 43-60.

- Sixsmith, Rebecca y Furnham, Adrian (2009): "A content analysis of British food advertisements aimed at children and adults". En, Health Promotion International, Vol. 25, $\mathrm{n}^{\mathrm{o}}$ 1, pp. 24-32.

- Stern, Susannah R. y Mastro, Dana E. (2004): “Gender Portrayals Across the Life Span: A Content Analytic Look at Broadcast Commercials". En Mass Communication and Society, Vol. 7, no 2, pp. 215-236.

- Valls-Fernández, Federico y Martínez-Vicente, José Manuel (2007): “Gender Stereotypes in Spanish Television Commercials”. En Sex Roles, n 56, pp. 691-699.

- Whipple, Thomas y McManamon, Kate (2002): "Implications of using male and female voices in commercials: an exploratory study". En Journal of Advertising, Vol. 31, n 2, pp. 79-91.

- Younis, José Antonio (2008): "Fotoperiodismo y relaciones de poder entre jóvenes e instituciones. Homenaje al profesor Manuel Martín Serrano”. En Mediaciones Sociales, ${ }^{\circ}$ 3, pp. 299-347. 